\title{
Evaluation of transverse cerebellar diameter to abdominal circumference ratio in prediction of intrauterine growth retardation
}

\author{
Saroj Mourya ${ }^{1 *}$, Harish K. Mourya², Mohan Makwana², Hanslata Gahlot ${ }^{1}$, \\ Suresh Verma ${ }^{2}$, Seema Sharma ${ }^{1}$
}

\author{
${ }^{1}$ Department of Obstetrics and Gynecology, ${ }^{2}$ Department of Paediatrics, Dr. S.N. Medical College, Jodhpur, Rajasthan, \\ India
}

Received: 25 March 2017

Revised: 03 April 2017

Accepted: 22 April 2017

\section{*Correspondence:}

Dr. Saroj Mourya,

E-mail: drsarojmourya@gmail.com

Copyright: $(\subset$ the author(s), publisher and licensee Medip Academy. This is an open-access article distributed under the terms of the Creative Commons Attribution Non-Commercial License, which permits unrestricted non-commercial use, distribution, and reproduction in any medium, provided the original work is properly cited.

\begin{abstract}
Background: Intrauterine growth restriction accounts for a significant increase in perinatal mortality rate as well as immediate neonatal morbidity and continuing long term disability in some of the survivors. A different clinical problem develops in infants of same weight but different gestational age therefore identification of high risk newborns based on gestational age and weight. Hence without an accurate knowledge of gestational age, the clinician is significant hampered in an attempt to differentiate truly growth restricted fetus from a patient with incorrect gestational parameters. TCD is emerging as a new sonografic parameter and least affected by fetal growth restriction while liver is most affected organ.

Methods: The patients were sonographically examined for TCD/AC ratio. The best cut-off value of TCD/AC ratio in predicting IUGR was determined by a receiver operating characteristic (ROC) curve. The fetus with a TCD/AC ratio greater than the cut-off value would be antenatally diagnosed as IUGR for every gestational week. Standard definition of IUGR was a low birth weight, less than the 10th percentile.

Results: Eighty pregnancies with suspected IUGR were analyzed. The prevalence of IUGR among the study group was $51.5 \%$. The best cut-off value of the TCD/AC ratio for predicting IUGR was $15.87 \%$, giving the sensitivity, specificity, positive predictive value and negative predictive value of $81.25 \%, 62.25 \%, 89.65 \%$, and $45.45 \%$, respectively.

Conclusions: The sonographic fetal TCD/AC ratio as a gestational age-independent, useful, feasible and sensitive method for antenatal diagnosis of IUGR, especially in pregnancy with uncertain gestational age. Routine TCD/AC ratio should be performed to diagnose IUGR.
\end{abstract}

Keywords: Abdominal circumference, Fetal transverse cerebellar diameter, Intra uterine growth restriction

\section{INTRODUCTION}

Intrauterine growth restriction accounts for a significant increase in perinatal mortality rate as well as immediate neonatal morbidity and continuing long term disability in some of the survivors. ${ }^{1}$ A different clinical problem develops in infants of same weight but different gestational age therefore identification of high risk newborns based on gestational age and weight. Hence without an accurate knowledge of gestational age, the clinician is significant hampered in an attempt to differentiate truly growth restricted fetus from a patient with incorrect gestational parameters. TCD is emerging as a new sonografic parameter and least affected by fetal growth restriction while liver is most affected organ. ${ }^{2}$ 
TCD is claimed to be more equivalent in certain situations like extremes of growth abnormalities and variations of fetal head shape such as dolicocephaly and brachycephaly. ${ }^{3-5}$ Therefore, it would seem reasonable to investigate any relationship between TCD and AC as a predictor of fetal growth abnormalities.

\section{METHODS}

This case control study was conducted at department of Obstetrics and Gynaecology, Mahila Chikitsalaya, SMS Medical College, Jaipur for a period of one year. Total 80 pregnant women in $3^{\text {rd }}$ trimester was selected and divided in two groups

- Group A was control group consisted of 40 cases with normal singleton pregnancy

- Group B was study group consisted of 40 cases with clinical suspicion of IUGR.

A discrepancy of 4 weeks in period of gestation and clinical examination was taken as evidence of IUGR. Period of gestation determined by either LMP or USG of $<20$ weeks if available. Multiple gestation and poly hydramnios are excluded from the study. In all cases, fundal height was measured in centimetres after that all patients underwent ultrasonography. TCD and AC was measured along with other parameters. TCD/AC*100 ratio was calculated for all cases.

TCD/AC ratio of study group was compared with mean TCD/AC*100 ratio of control group in accordance to gestation age. When it was two standard deviation (SD) above the mean it was taken as ultrasonographically IUGR case and is confirmed by post natal newborn assessment by expanded new Ballard score. New born weight was compared with weight normogram given by Meharban Singh. If it was $<10^{\text {th }}$ percentile for gestation age, it was diagnosed as a case of true IUGR.

\section{RESULTS}

Total no of 80 cases were studied. TCD/AC ratio was measured in all cases. TCD/AC ratio in control group with their mean TCD/AC ratio and mean \pm SD according to gestational age (Table1).

Mean of the mean TCD/AC ratio was 14.220 and mean SD was 0.455 . So, predictive value of TCD/AC ratio was 15.230 (Table 2).

TCD/AC ratio of all cases in study group was compared with mean TCD/AC ratio of control group according to gestational age and where it was $>2 \mathrm{SD}$ above the mean TCD/AC ratio of control group, it was taken as ultrasonically IUGR case (Table 3 ).

Then result was compared with post-delivery examination.
Table 1: TCD/AC ratio in control group according to gestational age.

\begin{tabular}{|c|c|c|c|c|c|c|}
\hline GA & TCD & $\mathrm{AC}$ & TCD/AC & $\begin{array}{l}\mathrm{TCD} / \mathrm{AC} \\
\text { mean }\end{array}$ & SD & $\begin{array}{l}\text { Mean } \\
+2 S D\end{array}$ \\
\hline \multirow[t]{4}{*}{32} & 38 & 265 & 14.3 & 13.80 & 0.396 & 14.590 \\
\hline & 38 & 280 & 13.5 & & & \\
\hline & 36 & 270 & 13.3 & & & \\
\hline & 38 & 270 & 14.07 & & & \\
\hline \multirow[t]{3}{*}{33} & 42 & 280 & 15.0 & 14.53 & 0.378 & 15.280 \\
\hline & 40 & 275 & 14.54 & & & \\
\hline & 38 & 270 & 14.07 & & & \\
\hline \multirow[t]{4}{*}{34} & 40 & 280 & 14.28 & 14.52 & 0.240 & 15.000 \\
\hline & 42 & 285 & 14.7 & & & \\
\hline & 43 & 290 & 14.82 & & & \\
\hline & 40 & 280 & 14.28 & & & \\
\hline \multirow[t]{3}{*}{35} & 45 & 300 & 15 & 15.26 & 0.197 & 15.650 \\
\hline & 46 & 300 & 15.3 & & & \\
\hline & 48 & 310 & 15.48 & & & \\
\hline \multirow[t]{6}{*}{36} & 42 & 316 & 13.29 & 14.16 & 0.777 & 15.716 \\
\hline & 40.7 & 313 & 13.0 & & & \\
\hline & 44 & 312 & 14.1 & & & \\
\hline & 41 & 276 & 14.8 & & & \\
\hline & 45 & 300 & 15.0 & & & \\
\hline & 41 & 276 & 14.8 & & & \\
\hline \multirow[t]{4}{*}{37} & 42 & 298 & 14.0 & 13.53 & 0.814 & 15.158 \\
\hline & 46.2 & 321 & 12.12 & & & \\
\hline & 42 & 299 & 14.0 & & & \\
\hline & 42 & 298 & 14.0 & & & \\
\hline \multirow[t]{6}{*}{38} & 46 & 324 & 14.1 & 14.25 & 0.488 & 15.227 \\
\hline & 41 & 305 & 13.4 & & & \\
\hline & 42 & 383 & 14.84 & & & \\
\hline & 46 & 310 & 14.8 & & & \\
\hline & 45 & 320 & 14.06 & & & \\
\hline & 46 & 320 & 14.3 & & & \\
\hline 39 & 46 & 325 & 14.15 & 14.15 & & \\
\hline \multirow[t]{9}{*}{40} & 43 & 351 & 12.25 & 13.82 & 0.811 & 15.440 \\
\hline & 41.8 & 318 & 13.14 & & & \\
\hline & 43 & 330 & 13.9 & & & \\
\hline & 45 & 326 & 13.8 & & & \\
\hline & 46 & 335 & 13.7 & & & \\
\hline & 48 & 325 & 14.7 & & & \\
\hline & 50 & 325 & 15.3 & & & \\
\hline & 43 & 330 & 13.9 & & & \\
\hline & 46 & 325 & 13.7 & & & \\
\hline
\end{tabular}

Table 2: Relationship of TCD/AC Ratio and gestational age in control group

\begin{tabular}{|lll|l|}
\hline $\begin{array}{l}\text { Weeks of } \\
\text { gestation }\end{array}$ & $\begin{array}{l}\text { No. of } \\
\text { cases }\end{array}$ & $\begin{array}{l}\text { Range of } \\
\text { TCD/AC }(\%)\end{array}$ & Mean \pm SD \\
\hline 32 & 4 & $13.33-14.30$ & $13.80 \pm 0.396$ \\
\hline 33 & 3 & $14.07-15.00$ & $14.53 \pm 0.378$ \\
\hline 34 & 4 & $14.28-14.82$ & $14.52 \pm 0.240$ \\
\hline 35 & 3 & $15.00-15.48$ & $15.26 \pm 0.197$ \\
\hline 36 & 6 & $13.00-15.00$ & $14.16 \pm 0.777$ \\
\hline 37 & 4 & $12.12-14.00$ & $13.53 \pm 0.814$ \\
\hline 38 & 6 & $13.40-14.84$ & $14.25 \pm 0.488$ \\
\hline 39 & 1 & 14.15 & - \\
\hline 40 & 9 & $12.25-15.30$ & $13.82 \pm 0.811$ \\
\hline Total & 40 & & $14.220 \pm 0.445$ \\
\hline
\end{tabular}


Out of 40 cases in study group 29 were diagnosed as IUGR by USG three false positive cases (Table 4). Out of 40 cases in study group 32 were true IUGR postnatally and 6 were missed by USG. According to this study sensitivity of this method is $81.25 \%$ and positive predictive value is $89.65 \%$ (Table 5 ).

Table 3: Relationship of TCD/AC Ratio and gestational age in study group.

\begin{tabular}{|c|c|c|c|c|c|}
\hline Gestational age & No. of cases & TCD/AC Ratio & Cases with TCD/AC \% > 2SD & True SGA & AGA \\
\hline 32 & 1 & 14.678 & SGA & SGA & \\
\hline 33 & 0 & - & - & - & - \\
\hline \multirow[t]{3}{*}{34} & 3 & 16.370 & SGA & SGA & \\
\hline & & 15.139 & SGA & SGA & \\
\hline & & 13.30 & AGA & SGA & \\
\hline 35 & 0 & - & - & - & \\
\hline \multirow[t]{4}{*}{36} & 4 & 16.37 & SGA & SGA & \\
\hline & & 15.50 & AGA & & AGA \\
\hline & & 13.60 & AGA & & AGA \\
\hline & & 15.59 & SGA & SGA & \\
\hline \multirow[t]{3}{*}{37} & 3 & 16.43 & SGA & SGA & \\
\hline & & 17.17 & SGA & SGA & \\
\hline & & 14.93 & SGA & SGA & \\
\hline \multirow[t]{9}{*}{38} & 9 & 14.63 & AGA & & AGA \\
\hline & & 14.16 & AGA & & AGA \\
\hline & & 17.00 & AGA & SGA & \\
\hline & & 17.17 & SGA & SGA & \\
\hline & & 15.50 & SGA & & AGA \\
\hline & & 15.70 & SGA & SGA & \\
\hline & & 15.90 & SGA & SGA & \\
\hline & & 17.30 & SGA & SGA & \\
\hline & & 16.53 & SGA & SGA & \\
\hline \multirow[t]{3}{*}{39} & 3 & 16.00 & SGA & SGA & \\
\hline & & 16.92 & SGA & SGA & \\
\hline & & 15.33 & SGA & SGA & \\
\hline \multirow[t]{17}{*}{40} & 17 & 17.00 & SGA & SGA & \\
\hline & & 14.17 & AGA & SGA & \\
\hline & & 16.78 & SGA & SGA & \\
\hline & & 15.90 & SGA & & AGA \\
\hline & & 15.70 & SGA & SGA & \\
\hline & & 13.00 & AGA & SGA & \\
\hline & & 15.54 & SGA & & AGA \\
\hline & & 15.70 & SGA & SGA & \\
\hline & & 16.15 & SGA & SGA & \\
\hline & & 15.70 & SGA & SGA & \\
\hline & & 16.07 & SGA & SGA & \\
\hline & & 16.42 & SGA & SGA & \\
\hline & & 14.68 & AGA & & AGA \\
\hline & & 14.60 & AGA & SGA & \\
\hline & & 15.86 & SGA & SGA & \\
\hline & & 14.51 & AGA & SGA & \\
\hline & & 15.50 & SGA & SGA & \\
\hline
\end{tabular}

\section{DISCUSSION}

Prenatal diagnosis of IUGR depends upon two factors.

- An estimate of gestational age.
- An accurate estimate of fetal size.

Unfortunately, the very biometric measurements used to demonstrate abnormal growth are also the once used to determine gestational age. 
Table 4: Predictability of IUGR by TCD/AC ratio (\%).

\begin{tabular}{|llllll|}
\hline GA (weeks) & No. of cases & $\begin{array}{l}\text { No. of cases with } \\
\text { TCD/AC }>\text { 2SD }\end{array}$ & $\begin{array}{l}\text { No. of true IUGR } \\
\text { cases }\end{array}$ & No. of false +ve & No. of false -ve \\
\hline 32 & 1 & 1 & 1 & - & - \\
\hline 33 & 0 & 0 & 0 & - & - \\
\hline 34 & 3 & 2 & 3 & - & - \\
\hline 35 & 0 & 0 & 0 & - & - \\
\hline 36 & 4 & 2 & 2 & - & - \\
\hline 37 & 3 & 3 & 3 & - & - \\
\hline 38 & 9 & 6 & 6 & 1 & 4 \\
\hline 39 & 3 & 3 & 3 & - & 6 \\
\hline 40 & 17 & 12 & 14 & 2 & - \\
\hline Total & 40 & 29 & 32 & 3 & - \\
\hline
\end{tabular}

Table 5: Sensitivity and positive predictive value of TCD/AC ratio for identification of IUGR.

\begin{tabular}{|c|c|c|c|}
\hline \multicolumn{4}{|c|}{ Examination on delivery } \\
\hline USG & IUGR+VE & IUGR-VH & \\
\hline $\begin{array}{l}\text { IUGR } \\
+ \text { ve }\end{array}$ & $\begin{array}{l}\text { True } \\
\text { +ve } 26\end{array}$ & $\begin{array}{l}\text { False } \\
\text { +ve } 3\end{array}$ & $\begin{array}{l}\text { All test } \\
\text { +ve } 29\end{array}$ \\
\hline IUGR & False & True & All test \\
\hline$-\mathrm{ve}$ & - ve 06 & - ve 5 & - ve 11 \\
\hline & All +ve 32 & All-ve 8 & 40 \\
\hline $\begin{array}{l}\text { Sensit } \\
\text { Positi }\end{array}$ & $\begin{array}{l}81.25 \% \\
\text { dictive valu }\end{array}$ & $P V)=89$ & \\
\hline
\end{tabular}

Some biometric parameter unaffected by growth abbreviation, providing standard against which dispraise growth could be compared. The cerebellum last to be affects by a decrease in blood flow. Moreover, liver is the most severely affected organ in decrease fetal growth. ${ }^{6}$

Campbell et al studied 87 patients; the mean TCD/AC ratio was $16.6 \%$ for the IUGR cases. Significantly larger than non IUGR cases $14.8 \%(\mathrm{p}<0.05)$. TCD/AC ratio was mentioned to have a sensitivity of $71 \%$, specificity $77 \%$, PPV 79\% and NPV (negative predictive value)) $68 \% .7,8$

Sagwan K studied 40 patients, sensitivity was $84 \%$ and PPV was $100 \%$. The mean value of TCD/AC ratio in study group was $14.92 \pm 1.28$ and in patient with confirmed SGA babies it was $15.87 \pm 0.92$ significantly higher than post delivery normal cases. ${ }^{9}$

Haller $\mathrm{H}$ et al studied TCD/AC ratio in 365 cases. A $\mathrm{TCD} / \mathrm{AC}$ ratio more than 15.5 was present in $85 \%$ of SGA infants. ${ }^{10}$

William $\mathbf{J}$ et al studied 825 low risk obstetric cases and found TCD/AC ratio was gestational age independent between 14 and 42 weeks with a mean of $13.68 \pm 0.96$. A value exceeding $2 \mathrm{SD}$ of mean was significantly associated with SGA infants. ${ }^{11,12}$
Tosnsong $\mathrm{T}$ and Wanapirak studied lone hundred and sixty-seven pregnancies with suspected IUGR were analyzed. The prevalence of IUGR among the study group was $51.5 \%$. The best cut-off value of the TCD/AC ratio for predicting IUGR was $15.4 \%$, giving the sensitivity, specificity, positive predictive value and negative predictive value of $73.26 \%, 80.25 \%, 79.75 \%$, and $73.86 \%$, respectively. ${ }^{13}$

In this study the mean value of TCD /AC ratio in control group was $14.22 \pm 0.91$ and in patient with confirmed SGA on post-delivery examination was >15.87 significantly higher $(\mathrm{p}<0.001)$ then in post-delivery normal cases $(p<0.001)$. In this study, out of 32 true IUGR cases were correctly diagnosed by TCD/AC ratio, hence sensitivity was $81.25 \%$, specificity $62.50 \%$, the PPV was $89.65 \%$ and NPV was $45.45 \%$. the result in this study are higher than Campbell et al but lower than Sangwan K et al results are comparable to $\mathrm{H}$ Haller and William j et al.

\section{ACKNOWLEDGMENTS}

Authors would like to give thanks to Department of radiology for their supports in study. Furthermore, Authors would like to give special thanks to Professor and Unit Head Vimala Jain madam for her outstanding support to conduct this study.

\section{Funding: No funding sources}

Conflict of interest: None declared

Ethical approval: The study was approved by the Institutional Ethics Committee

\section{REFERENCES}

1. Arias F: Fetal growth retardation: In practical guide to high risk pregnancy and delivery. 2nd ed. Delhi interprint. 2004: 301-17.

2. Golsdstein I, Reece EA, Gianluigi P, Bovicelli L, Hobbins JC. Cerebellar measurement with use in 
evaluation of fetal growth and development. Am J Obstet Gynecol. 1987;156:1065.

3. Chavez MR, Ananth CV, Smulian JC, Lashley, Ananath S, Kontopoulos EV et al. Fetal transverse cerebellar diameter normogram in singleton gestations with special emphasis in the in the 3rd trimester: A comparision with previously published normograms. Am Obstet Gynecol. 2003;189:1021-5.

4. Chavez MR, Ananth CV, Smulian JC, Vintzileos AM. Fetal transverse cerebellar diameter normogram in singleton gestations with special emphasis in the in the 3rd trimester. Am J Obstet Gynecol. 2004;191:979-84.

5. Chavez MR, Ananth CV, Kaminsky LM, Smulian JC, Yeo L, Vintzileos AM. Fetal transverse cerebellar diameter measurement for prediction of grstational age in twins. Am Obstet Gynecol. 2006;195:1956-600.

6. American college of obstetrician and gynecologist: Intrauterine growth restriction. Practice bulletin No. 12, Jan 2000.

7. Campbell WA, Nandi D, Vintizleos AM, Rodis JF, Turner GW, Egan JFX. Transcerebellar diameter to abdominal circumference ratio throughout pregnancy: A gestational age independent method to asses fetal growth. Obstet Gynecol. 1991;77:893-5.

8. Campbell WA, Nandi D, Vintizleos AM, Rodis JF, Turner GW. Use of transverse cerebellar diameter to abdominal circumference ratio to identify growth retardation. S. Obstet Gynecol. 1992;166:327.
9. Sangwan K, Sangita G, Puspa D. Evaluation of transverse cerebellar diameter to abdominal circumference ratio in prediction of intrauterine growth retardation. Obstet Gynecol. 1999;4:5.

10. Haller H, Petrovic O, Rukavina B. Fetal TCD/AC ratio in assessing fetal size. Int $\mathrm{J}$ Gynecol Obstet. 1995;50(2):159-63.

11. Meyer WJ, Gauthier D, Ramakrishnan V. Ultrasonografic detection of abnormal fetal growth with the gestational age independent TCD/AC ratio. Am J Obstet Gynecol. 1994;171:1057-63.

12. Meyer WJ, Gauthier DW, Goldenberg B, Santolaya J. The fetal TCD/AC ratio: A gestational age independent method of assessing fetal size. J Ultrasound Med. 1993;12(7):379-82.

13. Tonsong $\mathrm{T}$, Wanapirak $\mathrm{C}$, Thongpadungrogj $\mathrm{T}$. Sonographic diagnosis of intrauterine growth restriction by fetal transverse cerebellar diameter to abdominal circumference ratio. Int J Gynecol Obstet. 1999;66:1-5.

Cite this article as: Mourya S, Mourya HK, Makwana M, Gahlot H, Verma S, Sharma S. Evaluation of transverse cerebellar diameter to abdominal circumference ratio in prediction of intrauterine growth retardation. Int J Reprod Contracept Obstet Gynecol 2017;6:2466-70. 